\title{
Design of Cost Effective Antennas for Instrumentation Radars
}

\author{
L. Botha ${ }^{1}$
}

\begin{abstract}
The cost of antennas for instrumentation radars are determined by the development cost. By re-use of the reflector system cost effective antennas can be designed. The factors governing the design of such antennas are described here.
\end{abstract}

\section{INTRODUCTION}

Instrumentation radars which are used for dynamic measurements of targets have very specific antenna requirements. These radars normally have very stringent specifications on bandwidth and side lobe performance, while cost is also an important consideration. Because these radars are not production items where multiple units are built nor are they prototypes with short life spans, the antennas need to be designed and built to meet envisaged measurement programs which could span 10 to 20 years. The development costs for a 'one-off' reflector system can be very high. It is a distinct advantage to re-use the reflector system and to change only the feed system for different measurement radars. A specific example of reflector re-use will be given for an offset Gregorian antenna and the factors to be taken into account when planning to exchange feed systems on a regular basis will be discussed.

\section{DESIGN CONSIDERATIONS}

The following are very important considerations to be taken into account when designing an antenna for re-use.

\subsection{Electromagnetic design}

The starting point of any antenna design is the electromagnetic design that must be optimized to ensure that the antenna perform to specification and can perform its main function.

Because reflector antennas are quasi-optical systems [1], an optical design is done first. During this stage of the design the size of the antenna, size of the subreflector if applicable, f/D ratio and any offset angles if applicable are optimized. This is normally done using specific antenna design (synthesize) software such as Grasp [2] or Antenna-magus [3].

After the antenna size and geometry has been fixed, only the feed pattern can be used to change the antenna patterns. Although the basic frequency response of the reflector system is very wide, it is very difficult to design a feed that is constant with frequency. Most often the beam width of the feed will decrease with increasing frequency. This has the effect that for an optimum illumination at the center frequency, the reflector will be over illuminated at the lower frequencies and under illuminated at the higher frequencies. For wide bandwidth systems it is even possible that the first null of the feed pattern can move onto the reflector aperture.

To test the design and take into account the other elements of the reflector systems such as struts or arms, a full wave analysis using a program such as Feko [4] is now possible.

\subsection{Mechanical design}

Because of the use of the reflector system on a fast accelerating positioner, this place various mechanical constraints on the reflector system. The first constraint is the allowable weight. Weight reduces the acceleration possible with the motors and thus limits the dynamic performance of the radar system. For this reason a lightweight material such as composites is preferred.

The antenna must also be of sufficient strength so as not to break under maximum forces, including wind and potential water loads. Coupled to this is the stiffness required to ensure that the reflector system will not deform under acceleration conditions. Also important are the natural frequencies of vibration that can easily cause instability in the control loops of the positioner.

All of the above contributes to having a proper mechanical design with adequate analysis of the mechanical system done. This usually includes a finite element analysis of the mechanical system.

\subsection{Ergonometric design}

For the antenna to be effectively reusable, it is also important that a good ergonometric design be used. For very wide band design where feeds need to be changed, the ease of changing feeds and not losing the alignment of the reflector system is important. It is also important to have a mechanism to easily change the alignment of the feed so as to get the reflector system in proper focus.

This means that a proper feed mounting bracket with as many axis of adjustment as possible be used to

\footnotetext{
${ }^{1}$ Council for Scientific and Industrial Research, Defence Peace Safety and Security, PO Box 395, Pretoria, 0001, South Africa; e-mail: lbotha@csir.co.za, tel.: +27 128412899.
} 
mount the feed, and to focus the feed. It is possible to create a universal five axis of adjustment bracket. The only axis not adjustable is the polarization axis. The adjustment axes are:

- Forward / backward

- Left / right

- Up / down

- $\quad$ Tilt left / right

- Tilt up / down

\section{EXAMPLE ANTENNA}

To illustrate the design an example of a multipurpose antenna is given. This reflector has to serve two different radars. The first radar is a RCS measurement radar that must be dual polarized over a frequency band of 6.5 to $18 \mathrm{GHz}$. Because of the very wide bandwidth and thus control of the beam width of the feed, two feeds were used with overlapping frequencies. The second radar is an experimental tracking radar which need a mono-pulse antenna over a bandwidth of 8.5 to $10.5 \mathrm{GHz}$.

Table 1 shows the main specifications of the antenna.

\begin{tabular}{|c|c|c|}
\hline Specification & Antenna 1 & Antenna 2 \\
\hline $\begin{array}{l}\text { Total } \\
\text { Frequency } \\
\text { band }\end{array}$ & $\begin{array}{l}6.5 \text { to } 18 \mathrm{GHz}- \\
\text { sub-bands } 6.5 \text { to } 12 \\
\mathrm{GHz} \text { and } 11 \text { to } 18 \\
\mathrm{GHz}\end{array}$ & $\begin{array}{ll}8.5 & \text { to } 10.5 \\
\mathrm{GHz} & \end{array}$ \\
\hline Antenna Gain & $>35 \mathrm{dBi}$ & $>40 \mathrm{dBi}$ \\
\hline $\begin{array}{l}\text { Antenna } \\
\text { Sidelobes }\end{array}$ & $\begin{array}{l}<-20 \mathrm{dBr} \text { for all } \\
\text { frequencies and } \\
\text { polarisation } \\
<-25 \mathrm{dBr} \text { for } 90 \% \\
\text { of frequencies and } \\
\text { polarisations }\end{array}$ & $\begin{array}{l}<-20 \mathrm{dBr} \text { for } \\
\text { all frequencies } \\
<-25 \mathrm{dBr} \text { for } \\
90 \% \text { of } \\
\text { frequencies }\end{array}$ \\
\hline Feed Type & $\begin{array}{l}\text { Orthogonal dual } \\
\text { polarization feed }\end{array}$ & $\begin{array}{l}\text { Mono-pulse } \\
\text { feed }\end{array}$ \\
\hline
\end{tabular}

Table 1: Main specifications of two example antennas.

Figure 1 and Figure 2 show the feeds of the antennas and Figure 3 shows the tracking radar antenna.

\section{References}

[1] C.J. Sletten (ed), Reflector and lens antenna: analysis and design using personal computers, Artech House, 1988.

[2] Grasp software, Available: http://www.ticra.com/products/software/grasp.

[3] Antenna Magus, Available: http://www.feko.info/product-detail/antennamagus.

[4] Feko Product Detail, Available: http://www.feko.info/product-detail.

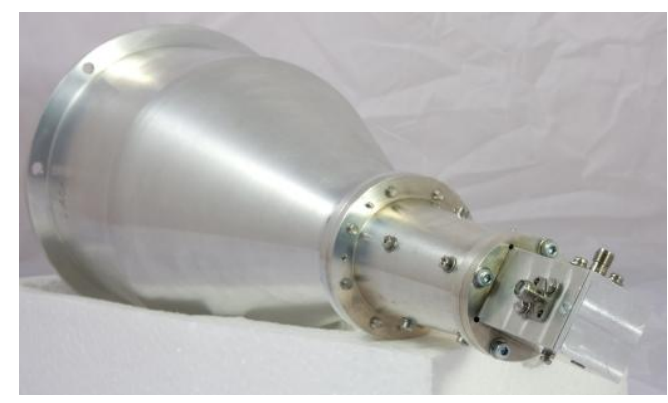

Figure 1: Low band dual polarized feed used for measurement radar.

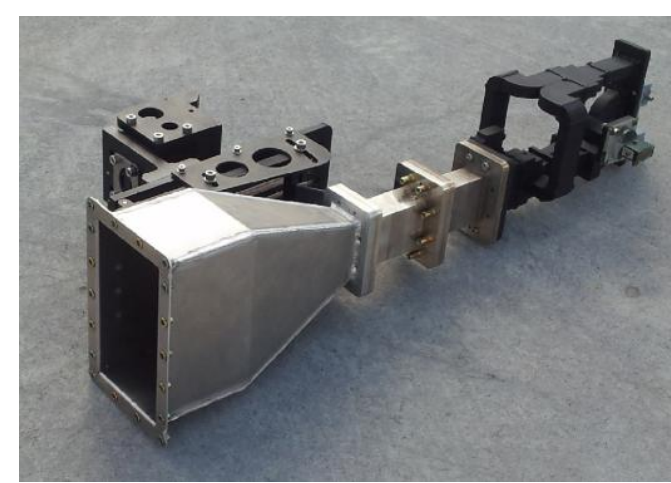

Figure 2: Feed for tracking radar showing mono pulse comparator and feed bracket.

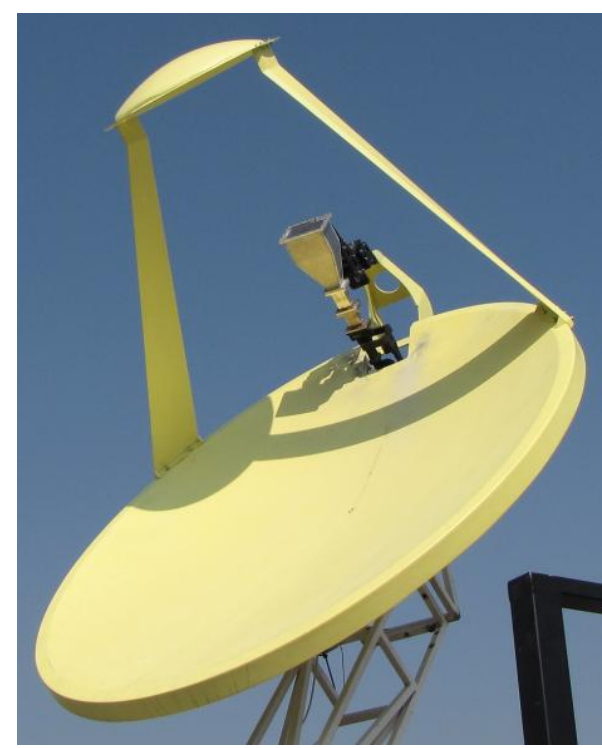

Figure 3: Reflector system of tracking radar antenna. 